\title{
Marketing Strategy Of Mixing Another Language In Adverts: Study of English Code-mixing and Code-switching In Indian Advertisements for Cold Drinks
}

\section{Priyanka Singh}

Research Scholar, Department of Humanities and Social Sciences, Rajiv Gandhi Institute of Petroleum Technology, Rae Bareli, Uttar Pradesh

\section{Dr. Saurabh Mishra}

Assistant Professor, Department of Humanities and Social Sciences, Rajiv Gandhi Institute of Petroleum Technology, Rae Bareli, Uttar Pradesh

\begin{abstract}
Code-mixing and code-switching are the marketing phenomenon researches have been working for around decades. While different types and their properties for code-mixing and code-switching have been well studied for most of the linguistic varieties as a marketing tool, very less is documented about how they are used as communicative and persuasive tool in advertisements. This analysis is an attempt to overcome with this gap by analyzing the level and describing the current phenomenon of English code-mixing and code-switching in Indian cold drink advertisements. It is noticed that the use of English codes in Hindi advertisements or even in few of complete English advertisements made specifically for Indian television is different from other genres of communication since they are creatively utilized to produce persuasive and convincing effects. The paper investigated the level of such mixing in Indian advertisements basically shown in Hindi speaking area, what kinds of English units are in use as well as certain other aspects related to English mixing which are employed as a persuasive device for the advertisements . English lexical mixing were found to be common English code-mixing elements, while simple sentences, out of all types of sentences, were the most frequent items appearing at the level of code-switching.
\end{abstract}

Keywords:

Advertising, Cold drink, codes, switching, mixing

Article Received: 18 October 2020, Revised: 3 November 2020, Accepted: 24 December 2020

1.

A) English is a widespread medium for connecting people, professionally and socially, across the globe. It is 'a 'contact language' between persons' (Firth 1996). Versatility of English as a medium/language has in due course earned various labels for it- 'English as a world language' (Mair 2003), 'World English' (BruttGriffler 2002) and English as a global language' (Crystal 2003 and Gnutzmann 1999). Roni (2008) proclaimed that English is more essential than other languages because it has become the lingua franca for international communication, allowing people speaking different languages to interact with each other. Undoubtedly now English is significantly dominating in several areas, such as technology, medicine, business, and mass media, and at the same time we cannot ignore the fact that inevitably other languages would be influenced by English.

English language was first introduced in India through contact with the British. Although India is a multilingual society, the expansion of English and borrowing between English and Indian languages were first witnessed as early as 1780s, nearly after 20 years of East India company in India, but it started spreading its branches widely in 1858, when the British Crown assuming direct control of India in the form of the new British Raj and in recent times this is also important from the globalization point of view. Today one cannot deny the fact that English is ubiquitous also in the areas of- mass media such as movie, radio, 
television programs and also in television commercials.

Not in contrast to the other languages, Hindi has adopted a variety of characteristics from English. Consequently, English has had an effect on Hindi language at all levels whether in phonology, morphology, semantics, and syntax, with one of the most remarkable influences being the mixing of English in Hindi language advertisements. The phenomenon frequently occurs in many genres of communication like speaking, writing and also in the pieces of media creations as well. Although it is also argued that-'pluri-centricity of English is overwhelming, and unprecedented in linguistic history. It raises issues of diversification, codification, identity, creativity, cross-cultural intelligibility, and of power and ideology' (Kachru 1996).

B) Code mixing and code switching have been defined by many researchers and linguists in various ways- Hymes (1974) defines CS as an optional use by a person aware with minimum two languages, in one conversation where as Auer (1995) proposed a newolog Code- alteration. Milroy and Muysken (1995) were seems to be agreed with the definition given by Hymes but Bokamba (1989) says it as blending of grammatical and or lexical units from the different language system within the limit of a sentence in a single conversation. On the other hand $\mathrm{H}$. Moradi (2014) has taken it as language alteration and interference for any language.

Most of the studies of code switching and code mixing in any language are done in spoken discourse (e.g. Poplock 1980). Switching, however in recent times has also been analyzed by a number of scholars who have taken an interest in this phenomenon in its written manifestations as it appear in advertising copy (Bhatia 2007 and Srima Nandi 2013). Switching as it occurs in written advertising will often depend upon the targeted audience based upon their categorization on the basis of- age, sex, socio- economic status etc. Many researchers have discovered the persuasive and manipulative power of English in advertising (T. Likhitphongsathorn \& $\mathrm{P}$. Sappapan, D. Luna et al. 2005), H. Mushtaq \& T. Zahra 2012) worked on code mixing and code switching of commercials but from the different perspective and again their work is based on data collection from the targeted audience.

The paper aims to study the code mixing and code switching aspect English in Hindi advertisements from a varied angle analyzed the data of commercials for a single type of product on individual basis and tried to find out the ratio of mixing. In a second phase we have also studied the ratio of grammatical units involved in mixing of these commercials.

\section{RESEARCH HYPOTHESIS-}

The study is based on the following hypothetical traits:

H1: Establishing that the deviations in Hindi advertisements through English mixing and switching happen in high frequency.

H2: English words are the highest unit of deviations amongst the total mixing and switching in Hindi Advertisements.

H3: This study of the alternate use of two or more languages in advertising conversations is developed in two distinct but related directions:

(i) Primarily in establishing the existence of deviations in between HindiEnglish language codes for valuing Hindi advertisements.

(ii) And secondly if the above question ends up with the positive response then what extent of such blending, what are its Inter-lexical, lexical and sentential units and is it in compatibility of learning English

\section{METHODOLOGY -}




\section{(i) Data collection-}

During the course of study for this qualitative and quantitative research we came across number of research papers analyzing the term and data from different angles. For instance, Elizabeth Martin (1998) collected data from A single magazine " $L$ ' Express" for the sake of analysis M. J. G. Vizcaino (2011) worked on data from particular airline and analyzed the element of humor because of CS and CM. H. Mushtaq and T. Zahra (2012) collected the data from three different channels between 8 to $9 \mathrm{PM}$ for three days and end up with the analysis of personal views of 30 individuals about CS and CM in these advertisements. M Santello (2013) limits his data collected from 8 English Italian Bilinguals. Srima Nandi (2013) dealt with 5 random advertisements from three different languages for analysis.

The data for this analysis were largely drawn from all time cold drink advertisements made for television and their availability on internet especially on YouTube. For the purposes of this analysis, primarily I brought all the advertisements in written form for several reasons. First of all, it is easier to manipulate than audio and visual recordings. Secondly, it is a relatively easy to go back to some particular advertisement for certain reason. Thirdly, in the interest of providing as detailed an analysis as possible, it seemed more beneficial to focus on code-mixing and code switching in written material, an area often ignored in research. Indeed, the structural flexibility of the code-mixed slogans found in advertising makes it extremely interesting from a linguistic point of view. Those who write advertising copy enjoy what Leech (1966) referred to as 'copywriter's licence'. This carte blanche authorizes them to (i) experiment with orthography in Tag Lines, (ii) invent new lexical items, (iii) produce language which appears nonsensical, and/or (iv) use the intrasentential switching of roles and registers, in addition to many other options, all of which provides a fascinating linguistic mixture for analysis.

\section{(ii) Research instruments-}

A coding table was created to systematically input the English units and nativized English words found in Indian Hindi cold drink advertisements. The number and frequency of each unit were counted for further analysis.

\section{DATA ANALYSIS-}

Having obtained a sufficient number of commercials, the entire list of ads was screened and rearranged to systematize the commercials for analysis. To observe the most recent and ancient trend of English code-mixing and code-switching in the commercials and to limit the area of research with maximum possible results only Hindi advertisements where chosen out of number of Indian languages. Our focus was placed on Hindi commercials composed from the very much beginning of the Hindi Television commercials to the present available cold drink commercials that have English codes.

\begin{tabular}{|c|c|c|c|c|c|c|c|c|}
\hline $\begin{array}{c}\text { S. } \\
\text { No. }\end{array}$ & Brands & $\begin{array}{c}\text { No. of ads } \\
\text { analysed }\end{array}$ & $\begin{array}{c}\text { Pure } \\
\text { ads }\end{array}$ & $\begin{array}{c}\text { mixed } \\
\text { ads }\end{array}$ & Sent. & Phrasal & $\begin{array}{c}\text { lexical } \\
\text { (words) }\end{array}$ & $\begin{array}{c}\text { Inter } \\
\text { Lexical }\end{array}$ \\
\hline 1 & FRUTI & 5 & NA & 5 & 55 & 2 & 6 & 0 \\
\hline 2 & 7 UP & 14 & NA & 14 & 21 & 13 & 43 & 0 \\
\hline 3 & MIRINDA & 7 & $1 \mathrm{H}$ & 6 & 23 & 20 & 33 & 0 \\
\hline & $\begin{array}{c}\text { MOUNTAIN } \\
4\end{array}$ & 5 & $1 \mathrm{H}$ & 4 & 5 & 1 & 8 & 0 \\
\hline 5 & SLICE & 5 & $2 \mathrm{H}$ & 3 & 3 & 2 & 1 & 0 \\
\hline 6 & MAAZA & 9 & NA & 9 & 3 & 5 & 37 & 0 \\
\hline
\end{tabular}




\begin{tabular}{|c|c|c|c|c|c|c|c|c|}
\hline 7 & FANTA & 11 & $1 \mathrm{H}$ & 10 & 25 & 10 & 29 & 14 \\
\hline 8 & LIMCA & 9 & $1 \mathrm{E}+1 \mathrm{H}$ & 7 & 20 & 13 & 28 & 6 \\
\hline 9 & SPRITE & 11 & NA & 11 & 22 & 3 & 49 & 0 \\
\hline 10 & $\begin{array}{l}\text { COCA } \\
\text { COLA }\end{array}$ & 21 & $1 \mathrm{H}$ & 20 & 25 & 20 & 117 & 3 \\
\hline 11 & $\begin{array}{c}\text { THUMPS } \\
\text { UP }\end{array}$ & 17 & $1 \mathrm{E}$ & 16 & 42 & 8 & 18 & 2 \\
\hline 12 & PEPSI & 18 & NA & 18 & 122 & 15 & 83 & 18 \\
\hline & Total & 132 & 9 & 123 & 366 & 112 & 452 & 43 \\
\hline
\end{tabular}

Table 1. Frequency of Pure and code mixed Indian advertisements with all its grammatical units

Every English item present at one place in the data was taken as one of the mixed units and for the sake of analysis process it was treated as one single unit. Here it is notable that though linguistically code mixing and code switching are two related but different terms, still we are not taking them separately for our analysis and they both are counted in same group. The study is based on all time cold drink audio- video advertisements, with a concentration on the written form of these commercials. Both English code-mixing and code-switching units inserted in the commercials were analyzed to examine the linguistic sphere of Hindi speaking audience with the study of frequency of English codes. The analysis began with counting pure English, pure Hindi and Hindi-English mixed advertisements followed by analysis of the Inter-lexical, Lexical, phrasal and sentential classification of codes of English language when used in the discourse of these Hindi commercials.

We have given the term of inter- lexical mixing to those items where mixing is within the word i.e. few syllable are of Hindi and few are of English. Lexical codes are those where there is code mixing of only one lexical item or word. For our analysis we have counted phrasal items for those units where more than one English word is used but not reaching to the status of a sentence and sentential codes are those units where a complete English sentence is inserted. Proper nouns are not listed in any particular language. They are counted within their discourse language.

All the English items in the commercials were listed and classified. They were then put into the data table and manually counted. The data was concluded and reported in the table to present the number of English elements and the frequency of usage. Explanation and examples were provided to illustrate the usage of English codes in these advertisements.

This analysis of the data is done in two parts: Prologue and Epilogue. In the prologue section we will analyze the data for the ratio of pure and code mixed advertisements, different types of units and various grammatical categories with their ratio within these units.

In the epilogue section of our research we will study the analyzed data in relation to the persuasion technique involved in these advertisements.

As we know that persuading someone is performing an act using some form of communication, usually language (Campbell \& Kirmani 2000) and in advertising persuasion is one of the most prominent elements (Geis 1998 \& A. Goddard 2003) therefore lastly we will examine this data as a tool of persuasion in the practice of code switching in advertisements.

\section{5. RESEARCH FINDINGS-}


The analysis of the data showed that 973 English units are employed in the 123 Hindi cold drink advertisements. However the numbers of analyzed advertisements are 132 out of which 2 were purely English and 7 were purely Hindi advertisements.

\begin{tabular}{|c|c|c|}
\hline Type of Advertisement & Number & Percentage \\
\hline Pure English & 2 & 1.51515152 \\
\hline Pure Hindi & 7 & 5.3030303 \\
\hline Mixed & 123 & 93.1818182 \\
\hline Total & 132 & 100 \\
\hline
\end{tabular}

Table 2. Frequency of Pure and code mixed Indian advertisements

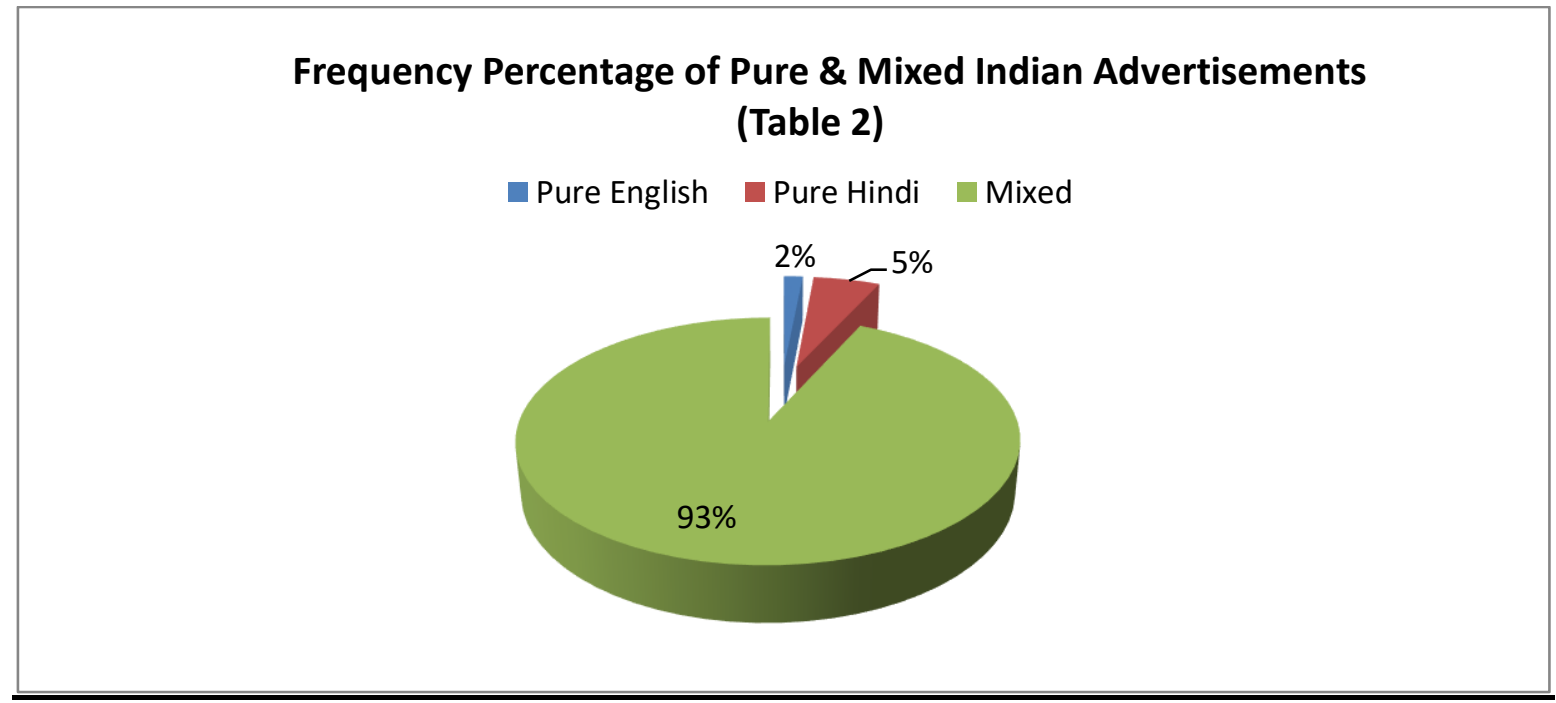

Chart Figure 1

While analyzing the level of English code mixing in sample data we have found that out of 132 commercials $123(93.18 \%)$ are having code mixing in their construction and out of rest nine 2 $(1.51 \%)$ are pure English adds and 7 (5.30\%) are pure Hindi. Few examples, out of analyzed data, for the English insertions in Hindi advertisements might be useful to illustrate these mixings

\section{Advertisement No.5 from Limca}

(A) State team ka youngest $12^{\text {th }}$ man hun boss (Sir I am youngest $12^{\text {th }}$ man of state team)

(B) Are kancho ki practice kaam mein lao (hey! utilize the practice of marbles)

\begin{tabular}{|c|c|c|}
\hline Types of English Units & $\begin{array}{c}\text { Number of Mixed } \\
\text { Units }\end{array}$ & Percentage \\
\hline Inter-lexical units & 43 & 4 \\
\hline Words & 452 & 46 \\
\hline Phrases & 112 & 12 \\
\hline Sentences & 366 & 38 \\
\hline Total & 973 & 100 \\
\hline
\end{tabular}

Table 3. Frequency of English units used in Indian advertisements 


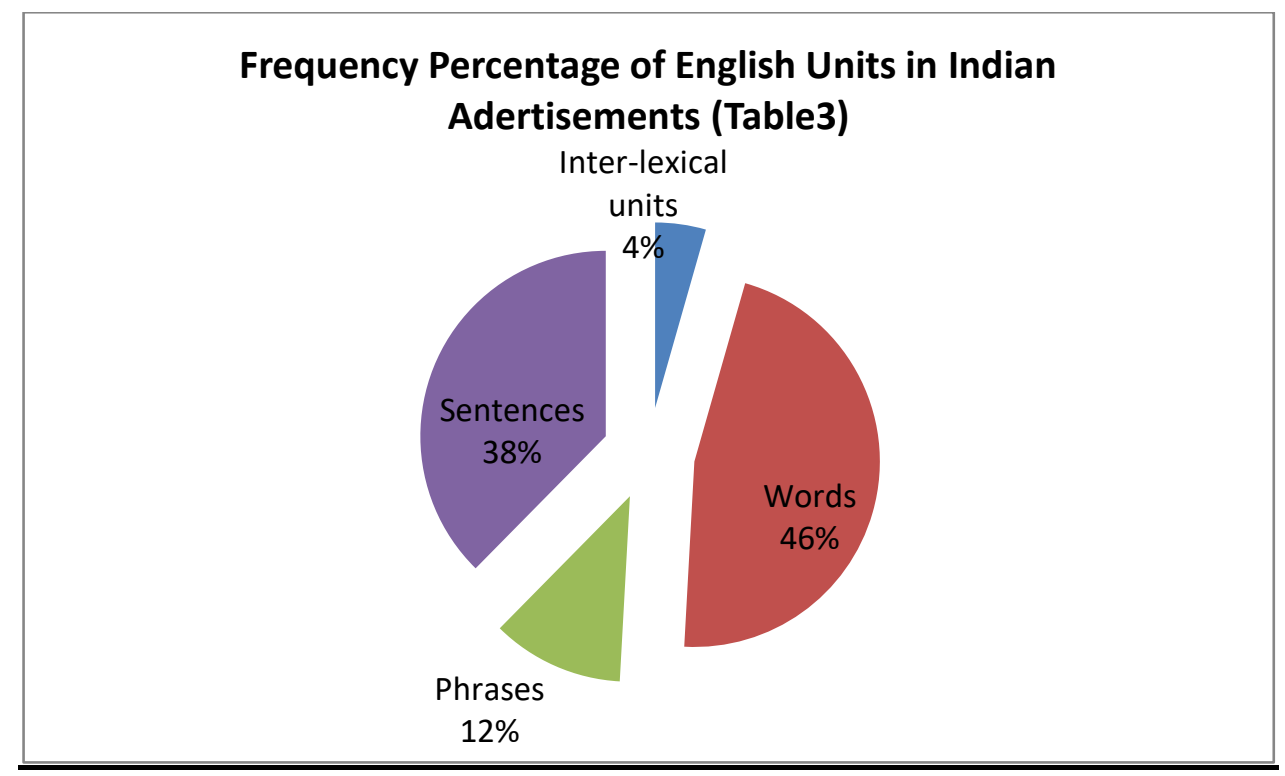

Chart Figure 2

When analyzing the level of mixing, it is as expected that English code-mixing outnumbered code-switching. Code-mixing was composed of 112 phrases (12\%), 452 (46\%) and 43 Inter lexical units (4\%), whereas code-switching had 366 sentences $(38 \%)$. For the sake of understanding, certain examples from the English inserted units are as follows:

\section{(A) Advertisement No. 21 of Cocacola for Sentential insertion (Hey! you return)}

(B) Advertisement No.6 of Pepsi for Phrasal insertion

(Sweet boys na)

Aren't they sweet boys?

(C) Advertisement No.6 of Sprite for Lexical insertion

Aap log fantastic the ab agle hfte milenge (You people were fantastic. Now we will meet in the next week)

(D) Advertisement No.10 of Pepsi for Interlexical insertion

Ye hai Youngistaan meri jaan (My darling this is youngistaan)

\begin{tabular}{|c|c|c|}
\hline Type of sentences & Number & Percentage \\
\hline Simple & 278 & 77 \\
\hline Compound & 35 & 10 \\
\hline Complex & 48 & 13 \\
\hline Total & 366 & 100 \\
\hline
\end{tabular}

Table 4. Classification and Frequency of English sentence classes used in these advertisements 


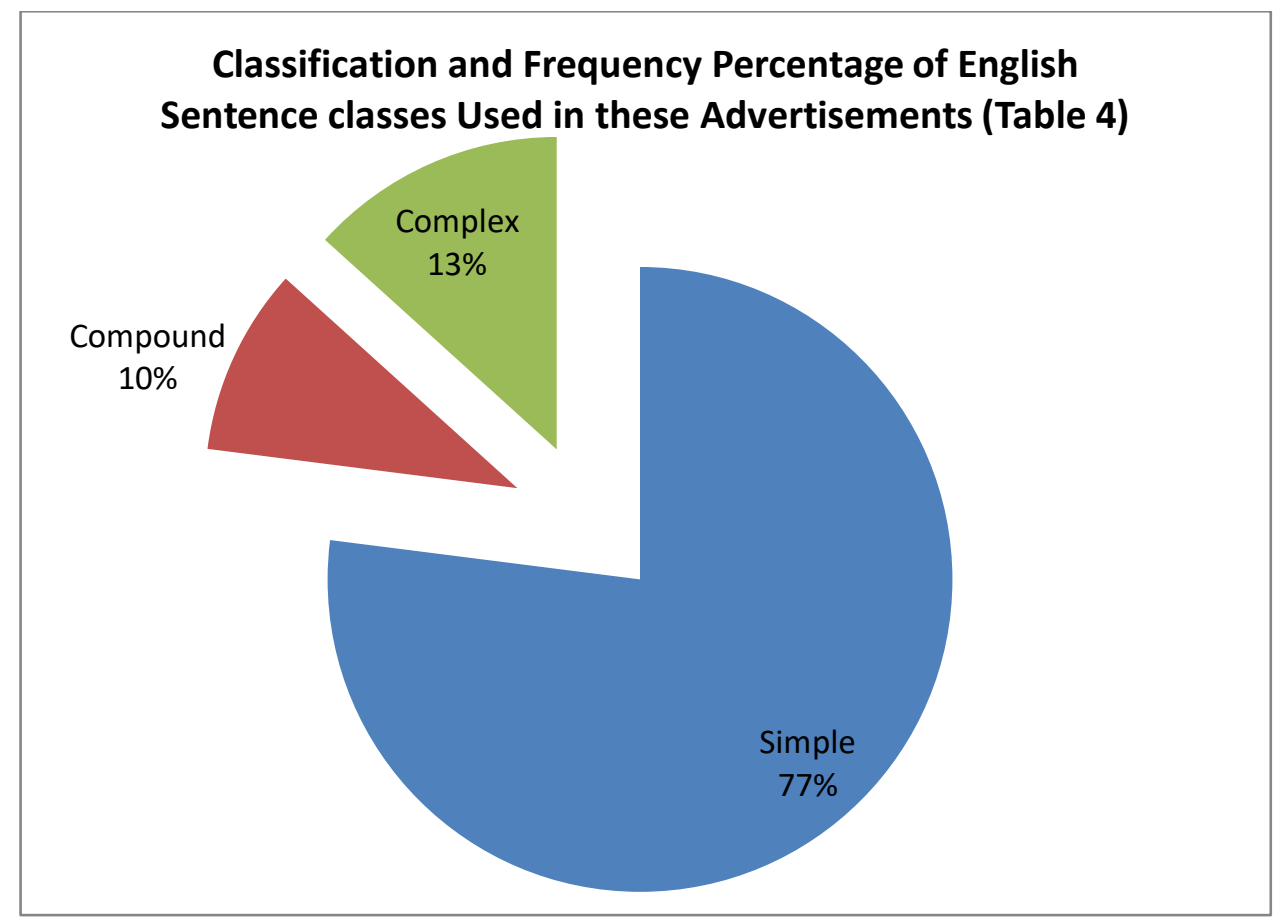

Chart Figure 3

Three types of English sentences, namely, simple sentences, compound sentences and complex sentences are employed in analyzed ads of Hindi cold drinks 415 sentences sharing $40.6 \%$ of all English units. It is necessary to note that certain English sentences were used in ungrammatical structures. Simple sentences recorded the highest number with 330 units $(79.51 \%)$, followed by complex sentences with 50 units $(12.04 \%)$ and compound sentences with 35 units (8.43\%) respectively. Examples of English sentences mixed into these commercials are shown as follows:

(A) Advertisement No.13 of Pepsi for Complex sentence insertion

And that's gona be a big one

(B) Advertisement No.8 of Pepsi for Compound sentence insertion

Receiving loud and clear

(C) Advertisement No.8 of Pepsi for Compound sentence insertion

I am so sorry

\begin{tabular}{|c|c|c|}
\hline Type of Phrase & Number & Percentage \\
\hline Noun & 27 & 24.1071429 \\
\hline Verb & 10 & 8.92857143 \\
\hline Adjective & 15 & 13.3928571 \\
\hline Adverb & 60 & 53.5714286 \\
\hline Total & 112 & 100 \\
\hline
\end{tabular}

Table 5. Classification and Frequency of English phrase classes used in these advertisements 


\section{Classification and Frequency Percentage of English phrase classes used in these Advertisements (Table 5) \\ Noun Verb Adjective $\square$ Adverb}
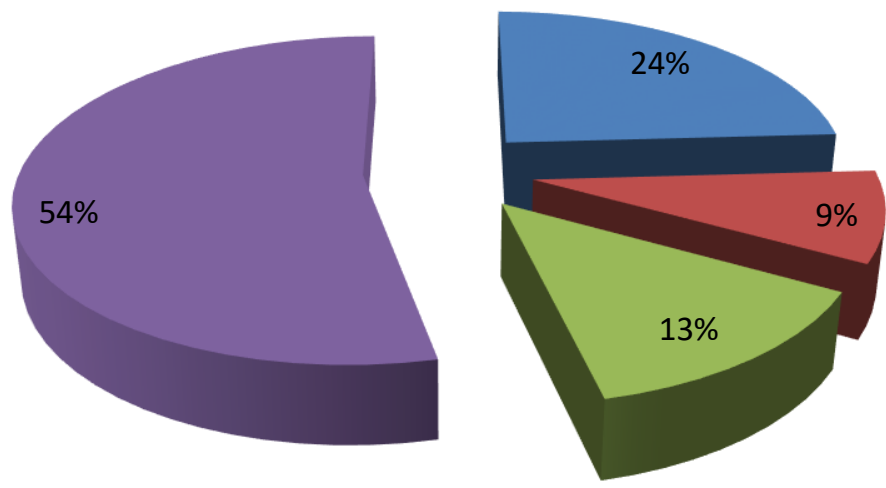

\section{Chart Figure 4}

There were 112 English phrases, sharing $10.9 \%$ of total English codes, found in the sampled lyrics of the commercials. Of the four types of phrases, adverb phrases had the highest number with 60 units $(53.57 \%)$, followed by noun phrases with 27 units $(24.10 \%)$, adjective phrases with 15units (13.39\%) and verb phrases with 10 units (8.92\%). Examples of English phrases mixed into the commercial lyrics are shown as follows:

\section{(A) Advertisement No.5 of Thumps Up for} Adverb Phrase insertion

Kyun ab dil maange no more
What happened? Now heart is demanding no more.

(B) Advertisement No.4 of Pepsi for Adjective Phrase insertion

Rest of the world to ghr gaya

Rest of the word has gone to home

(C) Advertisement No.12 of CocaCola for Verb Phrase insertion

Window shopping $\mathrm{kr}$ raha hun

(D) Advertisement No.3 of Pepsi for Noun Phrase insertion

Wo kya hai na mera style to you know Actually you know my Style na

\begin{tabular}{|c|c|c|}
\hline Type of Words & Number & Percentage \\
\hline Noun & 258 & 57.07964602 \\
\hline Pronoun & 23 & 5.088495575 \\
\hline Verb & 48 & 10.61946903 \\
\hline Adjective & 73 & 16.15044248 \\
\hline Adverb & 32 & 7.079646018 \\
\hline Preposition & 4 & 0.884955752 \\
\hline Conjunction & 7 & 1.548672566 \\
\hline Exclamation & 7 & 1.548672566 \\
\hline Total & 452 & 100 \\
\hline
\end{tabular}

Table 6. Classification and Frequency of English word classes used in these advertisements 


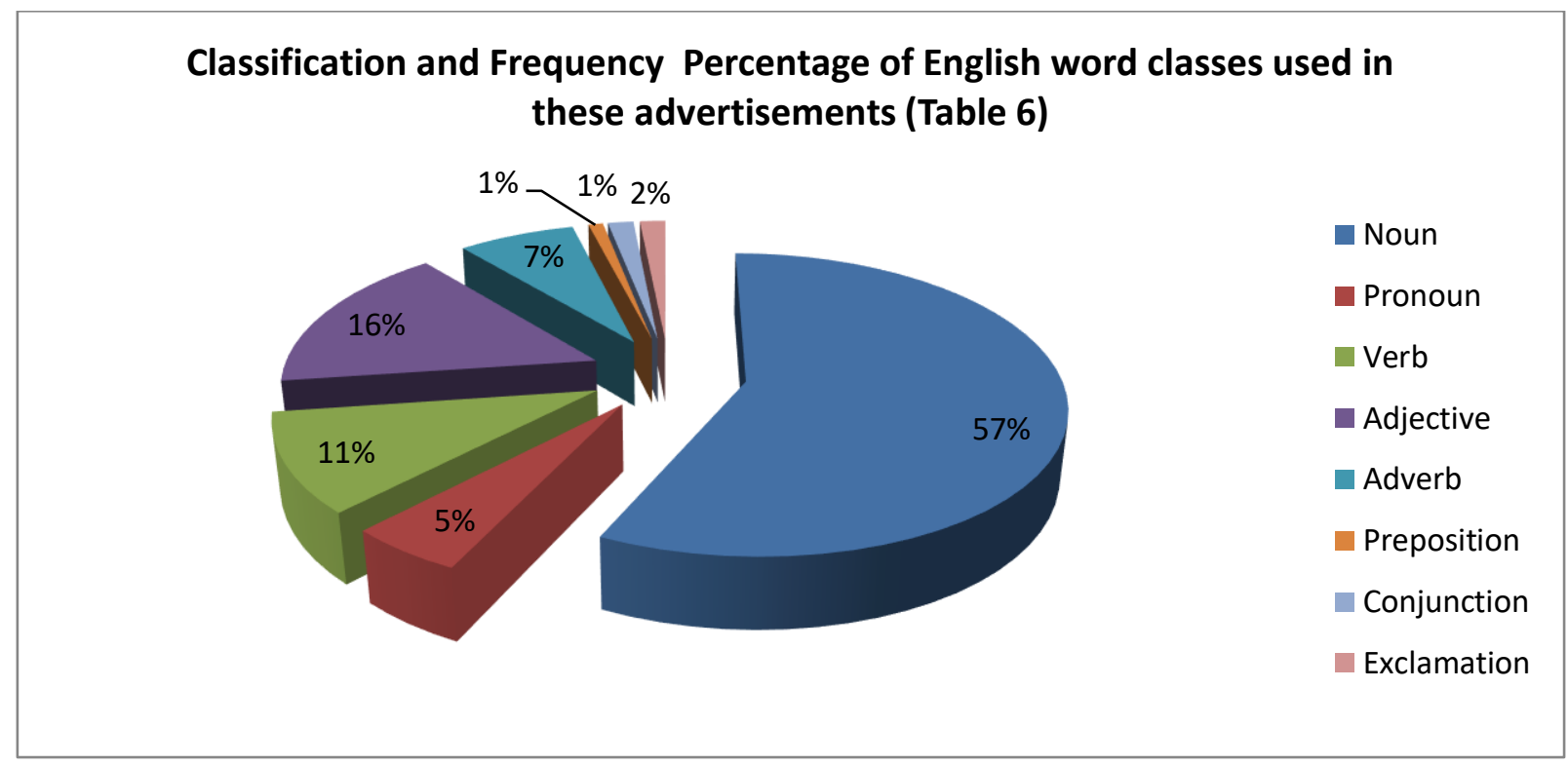

Chart Figure 5

Considering the code-mixing at the level of word, the obtained results show 452 words sharing $44.22 \%$ of all English codes, with nouns being the most popular English units used in lyrics of Hindi cold drink advertisements, having 258 units (57.07\%). Following this, 73 adjectives (16.15\%) were identified, and verbs were found at a total of 48 units $(10.61 \%)$. In addition to the top three word classes, there were 32 adverbs (7.07\%), 23 pronouns $(5.08 \%)$. Rest three prepositions conjunctions and exclamations are found only in single digits and they are 4 (0.88), 7 (1.54), 7 (1.54) respectively. Examples of English words mixed into these advertisement lyrics are illustrated as follows:

\section{(A) Advertisement No. 6 of 7 up for noun insertion}

Aaj ke baad sirf Hmari life badle hum nahi (From today onwards only our life changes not us)

(B) Advertisement No. 4 of Maaza for pronoun insertion

Pr aam to hr mausam mile hai baby (But baby we can get mangoes in all the seasons)

(C) Advertisement No. 3 of Sprite Verb insertion
Kuch to inko sikhana hoga ho jaye sb clear (Something we have to teach them so that everything will be clear)

(D) Advertisement No. 1 of Fanta for Adjective insertion Orangy bulbule jo muh mein bhare (Who is having his mouth filled with orangy bubbles)

(E) Advertisement No. 6 of Sprite for Adverb insertion

Guldaste si dikhti thi wo lagti thi garden

(F) Advertisement No. 10 of 7 Up for Preposition insertion

Dil bole up, I feel up

Heart says up, I feel up

(G)Advertisement No.3 of Thumps Up for Conjunction insertion

Uske haath mein.....hai so use mithi cheese pasand hai

Is in his hands so we can conclude the he loves sweet things

(H)Advertisement No.3 of Pepsi for Interjection insertion Hey wo dekh wahi Hey see one and the same 


\begin{tabular}{|c|c|c|}
\hline Type of Syllable in Inter-Lexical Units & Number & Percentage \\
\hline First Syllable & 31 & 72.09302326 \\
\hline Last Syllable & 12 & 27.90697674 \\
\hline Total & 43 & 100 \\
\hline
\end{tabular}

Table 7. Classification and Frequency of syllables in inter-lexical units used in these advertisements

Classification and Frequency Percentage of syllables in inter-lexical units used in these advertisements (Table 7)

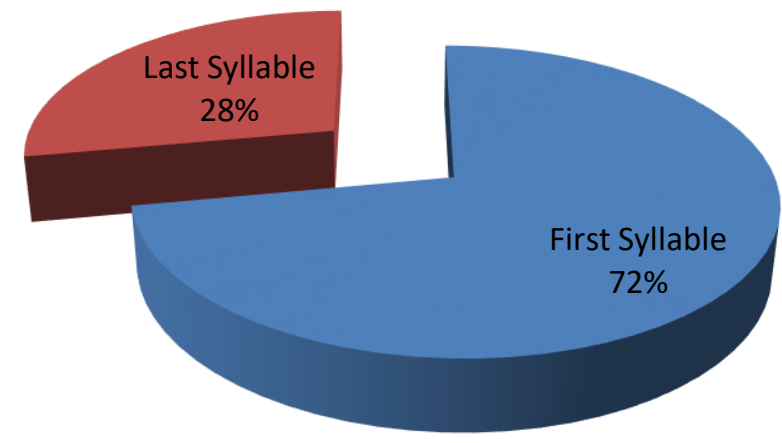

\section{Chart Figure 6}

Studying the code mixing at the inter-lexical level two types of units were found- Inter-lexical mixing for the first syllable- which contains 31 units $(72.09 \%)$ out of the total 43 units and mixing at the place of last syllable for 12 units $(27.9 \%)$.

\section{(A) Advertisement No.10 of Pepsi for First syllable insertion \\ Hum sb hai youngistaan \\ We all are youngistaan}

(B) Advertisement No.3 of Thumps Up for Last syllable insertion

I don't take bachchas

I don't select kids

\section{CONCLUSION-}

The data collected through the advertisements from different websites showed that out 132 advertisements 123 are having mixed codes of representation. Approximately $93.18 \%$ advertisements are using code-mixing in them and it was analyzed that code-mixing is prevalent in advertisements to a great extent. Similarly, the result of the questionnaire based survey showed that code-mixing leaves a very strong impact on the viewers as it helps the viewers to memorize the commercials easily and serves the purpose of effective communication. The impact of codemixing in advertisements on the younger generation is quite significant, as shown through the survey taken from the students of undergraduate studies. During the research it was also noted that majority of the students believed that code-mixing is a very useful tool for making language more effective in marketing and it is right to use any language other than Hindi in commercials since it attracts the viewers' attention. As the influence of English language in India is growing to a great extent, code-mixing is being accepted by the general public as a normal aspect of linguistic communication. It is being used very frequently and has become a part of the routine discourse. 
In order to 'belong' in the global scenario and in the global community, India's advertising industry is far ahead of its times to attain a distinctive identity of its own. This global identity and the need to belong and be at the level of other developed countries, India has been working hard to attain recognition at the international level. Thus the status of English in Indian advertisement is overwhelmingly high and equally envious.

\section{REFERENCES-}

[1] Auer, Peter, (1995). The pragmatics of code-switching: a sequential approach: from One Speaker, Two Languages. Cambridge.

[2] Bhatia, Tej K. (2007). Advertising and Marketing in Rural India: Language, Culture and Communication. Macmillan.

[3] Bokamba, E. (1989). Are there Syntactic Constraints on Code-mixing?. World Englishes.

[4] Brutt-Griffler, J. (2002). World English. Clevedon: Multilingual Matters.

[5] Crystal, D. (2003). English as a Global Language (Second edition). Cambridge University Press.

[6] Elizabeth Martin, (1998). The Use of English in Written French Advetising: A Study of Code- Switching, Code Mixing and Borrowing in a Commercial context. Studies in Linguistic Sciences: Volume 28, November 1 .

[7] Firth, A. (1996). The discursive accomplishment of normality On "lingua franca" English and conversation analysis. Journal of Pragmatics.

[8] Gnutzmann, C. (1999). Teaching and Learning English as a Global Language. Tu“bingen: Stauffenburg.

[9] H. Moradi (2014). A Survey on Code Mixing, Code Switching, Language Alteration and Interference. Indian Journal of Applied Research, Volume 4 , Issue 10.

[10] Hymes, D. (1974). Foundations In Sociolinguistics: An Ethnographic Approach. Longman.
[11] Kachru, Braj B.(1996). World Englishes: Agony and Ecstasy. Journal of Aesthetic Education, Vol. 30.

[12] Luna, David, Dawn Lerman, and Laura A. Peracchio (2005). Structural Constraints in Codeswitched Advertising. Journal of Consumer Research.

[13] Luna, David and Laura A. Peracchio (2005). Advertising to Bilingual Consumers: The Impact of CodeSwitching and Language Schemas on Persuasion. Journal of Consumer Research.

[14] Luna, David, and Laura A. Peracchio (2005). Sociolinguistic Effects on CodeSwitched Ads Targeting Bilingual Consumers. Journal of Advertising.

[15] Mair, C. (ed.). (2003). The Politics of English as a World Language. Rodopi.

[16] María José García Vizcaíno (2011). Humor in code-mixed airline advertising. International Pragmatics Association: Pragmatics.Milroy, L. \& Muysken, P. (1995). One speaker, two languages: Crossdisciplinary perspectives on code-switching. Cambridge University Press

[17] Mushtaq, H. and Zahra, T. (2012). An Analysis of Code-Mixing in Television Commercials. Language in India.

[18] Poplack, S. (1980). Sometimes I'll start a sentence in Spanish y termino en espaniol: Toward a typology of codeswitching. Journal of Linguistics.

[19] Roni, R. (2008). An analysis of IndonesianEnglish code mixing used in song lyrics of project pop (Master's thesis, School of Teacher Training and Education Muhammadiyah University of Surakarta, Indonesia). Retrieved from http://etd.eprints.ums.ac.id/3772/

[20] Santello Marco, (2013). Advertising to Italian English Bilinguals in Australia: Attitudes and Response to Language Selection. Applied linguistics. 
[21] Srima Nandi, (2013). The Status of English in Indian Advertisement. IJECT

Vol. 4, Issue Spl - 1, Jan - March. 